\title{
When Society Ages
}

\author{
V. G. Dobrokhleb ${ }^{a, b, *, \#}$ \\ ${ }^{a}$ Institute of Socioeconomic Studies of Population, Russian Academy of Sciences, Moscow, Russia \\ ${ }^{b}$ Institute for Demographic Research, Federal Center of Theoretical and Applied Sociology, Russian Academy of Sciences, \\ Moscow, Russia \\ *e-mail:vdobrokhleb@mail.ru \\ Received May 17, 2021; revised May 21, 2021; accepted May 27, 2021
}

\begin{abstract}
Russia is one of the demographically old countries of the world. The process of demographic aging in our country has a number of specific features associated with a change in the age structure of the population, which are determined by the second stage of depopulation; a significant lag in life expectancy indicators not only from economically developed but also from some developing countries; demographic asymmetry by gender; and rather low indicators of healthy life expectancy, which are calculated without accounting for the gender component, and with the burden of diseases dictated by age and accumulated before the age of 65 . The current situation increases the relevance of the search for an effective way out of the process of demographic aging, based on strategic approaches to the formation of public health throughout the entire life cycle of a person, including representatives of older age groups.
\end{abstract}

Keywords: age structure of the population, demographic aging, ageism, life expectancy.

DOI: $10.1134 / \mathrm{S} 1019331621050026$

One of the significant factors of global changes was the change in the size and age structure of the population of both individual countries or regions and the world as a whole. The dynamics of the population is made up of events in the life of each person. Demography as a science studies mass processes covering the totality of cases of birth, death, and migration. Demographic research proposes approaches that allow us to oppose new challenges, including the fourth industrial revolution, and in this context, it becomes basic for the survival of humanity and individual countries and regions [1-5].

The increase in the proportion and number of elderly and old people in the structure of the population (demographic aging) is a serious challenge for modern society [1]. Assessment of the demographic dynamics of the population is a fundamental scientific problem that is essential for the effective management of the socioeconomic development of territories. The concepts developed by European scientists back in the 20th century explaining the change in demographic trends are widely known [6-8]. However, for all the logic of, for example, the theory of demographic transition, it has several limitations, owing, in particular,

\footnotetext{
\#Valentina Grigor'evna Dobrokhleb, Dr. Sci. (Econ.), is a Professor and Chief Researcher at the Institute of Socioeconomic Studies of Population, Russian Academy of Sciences (ISESP RAS), and the Institute for Demographic Research, Federal Center of Theoretical and Applied Sociology, Russian Academy of Sciences (IDR FCTAS RAS).
}

to the differences in the sociocultural field and the institutional environment. The need to understand the significance of civilizational and regional specifics in defining demographic determinants is especially important for Russia in the 21st century.

\section{HOW TO DETERMINE THE LEVEL OF DEMOGRAPHIC AGING}

Demographic aging, the causes of which have been studied in detail [6,7], is understood as an increase in the proportion of elderly and old people in the total population. Population aging is the result of long-term shifts in fertility and mortality and their ratio, as well as, in part, in migration. There are two types of this process:

- "aging from below" is the result of a decrease in the birthrate; that is, there are fewer and fewer children in the structure and more and more people of older ages;

- "aging from above" is the result of an increase in life expectancy; that is, people live longer, which is due to a decrease in mortality at older ages in conditions of low fertility.

To assess the level of demographic aging of the population, the proportion of people over a certain age is used as a measure. For example, according to the scale of the famous Polish researcher E. Rosset, the age of 60 is considered the boundary of old age. Countries in which the share of people of 60 years and older 
is less than $8 \%$ are classified as demographically young; with the share of older ages above $12 \%$, the country is considered demographically old. Rosset identified four levels of demographic old age. If the older generation in the population is $18 \%$ or more, this means a very high level of demographic old age [6]. There is also another approach, often used in UN studies, in which the age of 65 is taken as the boundary of old age. Here we have another scale of estimates: if the proportion of people aged $65+$ in the population is less than $4 \%$, it is demographically young, and when this age category reaches more than $7 \%$, we are dealing with a demographically old population.

According to the UN 2019 Revision of World Population Prospects [9], by 2050 every sixth person in the world will be over 65 years of age ( $16 \%$ of the population), while in 2019 only every 11 th lived past this mark (9\%). By 2050, every fourth person in Europe and North America will be 65 years of age or older. Consider an important demographic milestone that was reached in 2018, when for the first time in history the number of people aged 65 and over exceeded the number of children under the age of five in the global population. The number of people aged 80 and over is increasing rapidly. This age group will triple, from $143 \mathrm{mln}$ in 2019 to $426 \mathrm{mln}$ in 2050.

At the beginning of 2020, the population of Russia was $146.749 \mathrm{mln}$ people. Among them, $8.339 \mathrm{mln}$ people were 65-69 years and $14.361 \mathrm{mln}$ were 70 years and older [10]. If we use the international border of old age, 65+, then we can calculate the level of demographic aging in our country: it is more than $15 \%$. Of course, according to this criterion, Russia belongs to demographically old countries. However, there are states-Japan (27\%), Italy (23\%), and Portugal $(22 \%)$ - that surpassed our country in this indicator [11].

Tula oblast is considered the most demographically old region of Russia, where people aged $65+$ make up $18.2 \%$, while the youngest subject of the Russian Federation is the Chechen Republic (4.3\%).

\section{FEATURES OF THE DEMOGRAPHIC AGING PROCESS}

The demographic resource within the framework of which human potential is formed has both quantitative and qualitative dimensions [12, 13]. One of the main qualitative indicators is life expectancy (LE). In most economically developed countries, it has increased continuously and rather rapidly since the 1990s. In Russia, a steady upward trend in life expectancy has been observed since 2004, having increased by 6.5 years by 2015 (from 64.9 years in 2003 to 71.4 years). However, compared with the best indicator of 1986-1987 (70.13 years), the growth was only 1.3 years. In 2016, the life expectancy at birth in Russia was 71.87 years ( 66.5 for men and 77.06 for women).
In terms of life expectancy, Russia lags behind economically developed countries, for example, behind the European Union, by almost ten years. In our country, significant differences remain in the life expectancy for men and women. In 2018, life expectancy at birth was 67.8 years for men and 77.8 years for women; in 2019, LE at birth for both sexes was 73.34 years.

The COVID-19 pandemic has led to population decline and impacted life expectancy. Thus, according to preliminary estimates, the resident population of the Russian Federation as of January 1, 2021, amounted to $146.2 \mathrm{mln}$ people. Since the beginning of 2020 , it has decreased by more than half a million (582 200 people, or $0.4 \%$ ). In 2019, the population decreased by 32100 people, or $0.02 \%$. At the same time, in 2020, the migration gain compensated for the natural decline only by $15.5 \%$ [14]. In 2020, life expectancy in the country fell for the first time after 2003. In terms of life expectancy, according to analysts, Russia will be able to return to the level of 2019 in 2024; in 2021, life expectancy will be 71.7 years [15].

Another distinctive feature of the demographic dynamics of Russia is the imbalance in the sex ratio in different age groups. Thus, at the beginning of 2019, the population of the Russian Federation was $146.8 \mathrm{mln}$ people. Among them, there were $68.1 \mathrm{mln}$ men (46\% of the population) and $78.7 \mathrm{mln}$ women (54\%). This male-to-female ratio remained virtually unchanged from the late 1980s. Note that in different age groups, it has significant differences. The unfavorable sex ratio in older age groups cannot be fully explained by the echo of the Great Patriotic War because the population of modern Russia was mainly born after that event. The total population, of course, could have been significantly larger if not for the significant human losses in 1941-1945. The demographic gap by sex is explained by the different mortality rates of men and women, formed by the quality of life of citizens, as well as gender characteristics of behavior. The high mortality rate of men, on the one hand, is due to the spread of bad habits (tobacco smoking, alcohol consumption, etc.) and an insufficient level of self-preserving behavior, and on the other, institutional costs, including the low quality of medical care, problems of its accessibility in small towns and rural localities, high prices for effective drugs and innovative medical technologies, and poverty.

Life expectancy is an exceptionally important indicator. However, not only prolongation but also the possibility to increase a long healthy life is becoming more and more important. This is what becomes the main criterion for assessing the effectiveness of social policy and health protection. According to the results of a selective observation of the state of health of the population, conducted by the Federal State Statistics Service of Russia (Rosstat) in 2019, about 7\% of 
respondents of all ages defined their health as "poor," including about $1 \%$ as "very poor." With age, selfassessment of health becomes significantly lower. Elderly women assess it more negatively than their male peers. Note that $22.6 \%$ of men and $23.9 \%$ of women over working age indicated that their health was "poor" and "very poor."

Rosstat has calculated healthy life expectancy (years to live without any major health problems). This indicator was 60.3 years for the country. Regional differences in healthy life expectancy (HLE) were identified. For example, HLE of residents of Chukotka is 49.1 years, and that in the Republic of Ingushetia, 67.2 years. Rosstat does not provide data on sex and age. Unfortunately, in the indicators of the National Projects, HLE does not provide for considering its gender specificity. According to the May 2018 Presidential Decree of [16], the heathy life expectancy of Russians should reach 67 years by 2024 . The same decree provides for an increase in life expectancy to 78 years by 2024 (by 2030, to 80 years).

Researchers continue to improve the methodology for assessing the problems of population aging, which allows comparison of differences both at the global level and between countries. A number of age-related diseases have been identified from a complete list of their causes. In connection with mortality rates, this approach helps to measure both life expectancy and the health of the population, as well as to avoid setting arbitrary age thresholds. The proposed new indicator makes it possible not only to use information about the chronological age but also to operate with data on the state of health and the severity of diseases in the aging population. However, for example, among countries with similar levels of age-related overall standardized mortality burden, disease burden accumulation patterns differ, with some populations beginning to feel it at an earlier age than others. Globally, the median age for aging is 65 years. Note that, for residents of Japan and Switzerland, it begins at 76.1 years. The top five slowly aging countries include France (76 years), Singapore (76 years), and Kuwait (75.3). In Russians, a set of diseases characteristic of old age appears at the age of 59. According to this indicator, the Russian Federation took 160th position in the ranking compiled by scientists [17].

Revealing the features of the demographic aging process in Russia is of fundamental importance for making decisions in the field of social policy. These features include the following:

- changes in the age structure of the population against the background of low birth rates associated with the second stage of depopulation in Russia;

- in terms of life expectancy for both women and men, Russia lags significantly behind not only economically developed but also a number of developing countries; der;

- the prevailing demographic asymmetry by gen-

- low indicators of healthy life expectancy, which are calculated without considering the gender component;

- the age-related disease burden that accumulates before age 65 .

\section{DEMOGRAPHIC DYNAMICS AND SOCIAL CHANGE}

The change in the age structure caused by the process of demographic aging gives rise to social and economic challenges [18]. Most often, population aging is associated with problems for the economy, primarily for the labor market [19]. Rosstat sample surveys of labor show that in December 2020, in the structure of labor in Russia, the population of 60-69 years old was 6\% (4.5 mln people), and those aged 70 and over, $0.4 \%$ (about $0.3 \mathrm{mln}$ people). Researchers note a significant decrease in the employment of people over working age, which occurred in 2017. While in 2016 almost every third pensioner participated in the labor market (29.8\%, $7 \mathrm{mln}$ people), in 2017, only every fifth did $(20.1 \%, 7.3 \mathrm{mln}$ people). Subsequently, the employment rate of older people increased slightly: in 2019 , this figure was $21.3 \%$ ( $7.9 \mathrm{mln}$ people) [20].

The researchers conclude that global strategic changes in the labor market for the older generation are changes in the retirement age and a possible delay in retirement due to various factors, including the use of flexible working hours and training and retraining of older employees [21].

In Russia, in connection with the 2018 pension reform, the boundaries of age groups was changed by law: until January 1, 2019, inclusive, men aged 60 and over, and women aged 55 and over belonged to the age group older than the working age. From January 1, 2020, men aged 61 and over, women aged 56 and over were added to this group. In 2020, the population over the working age was $36.6 \mathrm{mln}$ people. Compared to 2019 , this age group decreased by almost $1.4 \mathrm{mln}$ people. The initiators of this reform justified the need for its implementation by the fact that the life expectancy of older citizens had increased, and their health had improved so much that they could work longer and retire later. According to a Rosstat survey conducted in August 2020, the labor force was $75.3 \mathrm{mln}$ people, or $51 \%$ of the total population of the country: $70.5 \mathrm{mln}$ people were employed in the economy, and $4.8 \mathrm{mln}$ people were unemployed. The employment of the population amounted to $97.3 \%$ compared to the corresponding period of the previous year, and unemployment, $147.6 \%$, respectively. The COVID-19 pandemic has had a certain impact on employment. The highest unemployment rate was observed among preretirees. Thus, the goal of the pension reform to change the ratio between the resources of the Pension Fund of the 
Russian Federation and their obligations to pensioners was not achieved. Its implementation did not lead either to an increase in the number of the employed or to an increase in life expectancy [22].

In Russia, the access of older employees to paid employment is difficult, including due to the spread of ageist stereotypes. Overcoming them requires changes in the system of values, psychology, culture, health care, education, politics, and international relations. In other words, they should cover almost all spheres of public and private life. Note that society can both effectively respond to demographic changes and remain captive to social stereotypes. Ageism leads to stigmatization of older people, defining them as not full-fledged members of society, which limits their rights and opportunities in various spheres of life.

Scientists confirm that in modern society the authority of the elderly and old people is falling. The ability to stay young, healthy, and full of vitality is seen as a moral obligation, while aging and illness are considered unacceptable wrongdoings. The spread of ageism affects both the elderly and other age groups. In these conditions, even in the family, the elderly and old people play a lesser role in comparison with the previous forms of family ties. The "uselessness" attributed to old people is often the cause of their depression and suicide [23].

Two different approaches to assessing population aging have emerged. On the one hand, attention is focused on its socioeconomic costs; on the other hand, older people are increasingly seen as fullfledged participants in the process of socioeconomic development of society. About 40 years ago, in 1982, the First UN World Assembly on Aging was held, where the 62-point Vienna International Plan of Action on Aging was proposed. In 1991, the General Assembly endorsed the 18-point United Nations Principles for Older Persons, which formulate approaches to issues of independence, inclusion, care for older people, self-fulfillment, and respect for the dignity of older age groups in society. The International Conference on Aging (1992) adopted an Action Plan and Declaration on Aging. At the suggestion of its participants, the UN General Assembly proclaimed 1999 the International Year of Older Persons. Today the International Day of Older Persons is celebrated on October 1. The Second World Assembly on Aging was held in 2002 in Madrid. The Madrid International Plan on Aging called for the potential of older people to be used at all levels [9].

A deeper understanding of a person in today's diverse world allows the use of the gender approach. It should be remembered that there are more women among older people in Russia. This requires, on the one hand, more actively addressing the issues of supermortality of Russian men and, on the other, expanding opportunities for older women and men to participate fully in the life of society.
Problems of achieving gender equality have become a part of many international programs and documents [24]. Gender equality is not only a fundamental human right but also an essential foundation for peace, prosperity, and sustainable development. The report on the implementation of the Sustainable Development Goals (SDGs) in Russia pointed to the persistence of inequality between men and women. It was explained by "the remaining elements of the patriarchal way of life and not by the inequality of opportunities."

According to the Citizens' Review on SDG implementation in Russia [25], based on a study by the World Economic Forum, gender equality in the country has been achieved by $70.6 \%$. In terms of "health and life expectancy" and "accessibility of education," Russia is among the leaders among 153 states. The Russian Federation has taken certain steps towards achieving Sustainable Development Goal 5 ("Gender Equality"). For example, the list of jobs in which the employment of women is prohibited has been reduced from 456 to 100 positions [26]. At the same time, it is necessary to balance and consider possibilities, including physical ones, in the formation of professional standards and labor standards.

Note that in terms of the "Gender Equality" indicator, over the past 14 years, the Russian Federation has been worsening its position. In the ranking of the Gender Gap Index [27] in 2006, the country was ranked 49th, while in 2016, 75th, and in 2020, 81st among 153 countries. The positions of our country declined in terms of "economic participation and opportunities" (22nd in 2006 and 33rd in 2020) and "political participation" (108th in 2006 and 122nd in 2020). According to the estimates of the International Labor Organization [28], the gender pay gap in Russia-27.9\% - is not caused by the objective conditions of the labor market. As evidenced by the data of Russian trade unions [29], the differences reach an average of $40 \%$. The gap in the size of pensions for men and women increased from 5.5\% in 2016 to $11 \%$ in 2018 . There is no funding for the adaptation and integration program for external migrants, highlighting women as a particularly vulnerable group. The gender orientation of state statistics, including migration statistics, is weakly expressed. Women are underrepresented in political bodies: in 2019, the proportion of women in the lower house of parliament was $15.8 \%$ and in the upper house, $18.2 \%$; in regional parliaments, the number of women does not exceed $15 \%$ [30]. The demographic asymmetry and gender roles in older age groups are acquiring significant importance. In many countries, women are more likely than men to live to old age. In Russia, the number of elderly and old women exceeds their male peers by more than 15 million.

Social, technological, and demographic transformations influence the dynamics of social roles. The 
most important change is an increase in the share of women in paid work around the world, including in Russia. The number of families with traditional gender roles, where a woman is only a housewife and homemaker, has decreased sharply [31]. In this regard, the question arises of who will take care of children and frail elderly people, and whether measures of state support replace or supplant help within the family, or only complement it. Most of the problems are related to the fact that frail or disabled elderly people do not have family members to care for them. Women make up the largest segment of older people in need of care.

Russia belongs to countries with low per capita income. Under these conditions, a survival strategy is becoming an integral part of the life of elderly Russians. Note that the reduction in mortality and the improvement in the quality of life of people in this category are determined by far not only by the quality of medical care. Healthy food and healthy habits are essential, which depends both on the general economic situation and on the material well-being of citizens. However, it is difficult to talk about the prerequisites for a long life in the face of the falling real incomes of the population, economic instability, and international sanctions.

A distinctive feature of the population aged $65+$ is its serious vulnerability during the COVID-19 pandemic. Self-isolation, according to many researchers, negatively affects the body of older people. The pandemic that began in 2019 has not yet been overcome. According to Johns Hopkins University, as of February 5, 2021, nearly $105 \mathrm{mln}$ people in the world had confirmed coronavirus cases, $58.3 \mathrm{mln}$ had been cured, and more than $2.2 \mathrm{mln}$ had died. Over $44.2 \mathrm{mln}$ people are in the active stage of the disease. In terms of the number of cases, our country is in fourth place in the world. In this negative rating, the United States holds first place at more than $26.6 \mathrm{mln}$ people, the second place is India with over $10.8 \mathrm{mln}$, and the third is Brazil with almost 9.4 mln cases [32]. The limitations that older people face during the pandemic have been identified. These include the difficulty of accessing medical services, the lack of support in the event of infection with the coronavirus, and a reduction in medical care for diseases not related to COVID-19 (mental, cardiovascular, neurodegenerative, and other age-related disorders). Self-isolation can exacerbate some of the mental problems in older people and have a negative impact on their psychological status. The digital divide can make it difficult to use new technological devices for social networking. Older people living alone or in difficult life situations may have difficulty purchasing food and medicine. The problems that have emerged against the background of the spread of a new type of coronavirus infection are not so much medical or biological as political and social. Therefore, Russia will have to develop and propose a course corresponding to the conditions of life for the current and future generations.
Researchers point out that the social health of society depends on the attitude towards older people, the formation of a new culture of aging, including the social policy of the state, and everyday interactions [34].

According to the latest public opinion polls, old age in our country begins at the age of 62 . With the current lifestyle, women assume that they will live to 81 years, and men, to 74 years. The respondents believe that in better conditions they could live to be 85 years old. The main problems of older Russians are poverty and low pensions $(71 \%)$, deteriorating health and illness (44\%), a feeling of being useless and unclaimed (19\%), and loneliness (17\%). More than half of the respondents (54\%) noted that those around them respect older people, but $43 \%$ do not share this opinion [33]. The demographic trend of population aging dictates the need to change attitudes towards older people in society, to overcome ageism.

Social reforms are assessed by their effectiveness. It is hardly possible to talk about the positive consequences of the latest pension reform in Russia, not least because it does not take into account the structure of mortality and morbidity of the population of preretirement and retirement age (within its old boundaries). Note that $74 \%$ of the population expect that the social amendments introduced into the Constitution of the Russian Federation in 2020 will be implemented [35]. The authorities must learn to respond to the demands of older people, skillfully use their potential, implement strategic approaches to the formation of public health throughout the entire life cycle of a person, and develop the social policy of the state, where new control technologies are skillfully combined with rights and freedoms, including those of the older generation. Of course, one should agree with the opinion of RAS Corresponding Member A.V. Yurevich [23] that the development of the "ideology of old age" can become one of the fundamental scientific tasks of significant applied value. This requires the integration of efforts of scientists, including gerontologists, demographers, psychologists, sociologists, and economists.

\section{REFERENCES}

1. F. Alper, A. Alper, and O. Ucan, "The economic impacts of aging societies," Int. J. Econ. Financial Issues 6 (3), 1225-1238 (2016).

2. V. G. Dobrokhleb and V. N. Barsukov, "Demographic theories and the regional aspect of population ageing," Econ. Soc. Changes: Facts, Trends, Forecast, No. 6, 89-103 (2017).

3. A. Golini, "Demographic trends and aging in Europe: Prospects, problems, and policies," Genus, No. 53, 33-74 (1997).

4. M. Kaplan and M. Inguanzo, "The social, economic, and public health consequences of global population 
aging: Implications for social work practice and public policy," J. Soc. Work Glob. Comm., No. 1, 1-12 (2017).

5. R. Lee and A. Mason, "Population aging, wealth, and economic growth: Demographic dividends and public policy," WESS background paper. https://www.un.org/development/desa/dpad/wpcontent/uploads/sites/45/PDFs/WESS/wess_bg_papers/bp_wess2007_lee_mason.pdf.

6. E. Rosset, Aging Process of Population (Pergamon, London, 1964).

7. A. Sauvy, La théorie générale de la population, 3rd ed., Vol. 2: La vie des populations (Presses universitaires de France, Paris, 1963).

8. W. S. Thompson, "Population," Am. J. Sociol. 34, 959-975 (1929).

9. 2019 revision of world population prospects. https://population.un.org/wpp/. Cited February 20, 2021.

10. Population distribution by age groups. https://docviewer.yandex.ru/view/0/?*=uWu4HWW2hn1vY\%2BH19LS\%. Cited March 10, 2021.

11. 10 countries with the oldest populations in the world. https://news.rambler.ru/sociology/42809939/?utm_content $=$ news_media\&utm_medium $=$ read_more\&utm_source $=$ copylink. Cited March 10, 2021.

12. N. M. Rimashevskaya, Man and Reforms: Secrets of Survival (ISEPN RAN, Moscow, 2003) [in Russian].

13. Yu. V. Yakovets, V. G. Dobrokhleb, T. Yu. Yakovets, et al., Critical Situations and Prospects of Sociodemographic Dynamics of Russia and Other BRICS Countries (Prospekt, Moscow, 2017) [in Russian].

14. Demographics as of January 1, 2021. https://rosstat.gov.ru/folder/12781. Cited March 10, 2021.

15. Life expectancy in Russia during the pandemic decreased by 2 years. https://news.mail.ru/society/45523761/. Cited March 14, 2021.

16. Decree of the President of the Russian Federation of May 7, 2018, No. 204, On National Goals and Strategic Objectives of the Development of the Russian Federation for the Period up to 2024.

http://www.kremlin.ru/acts/bank/43027. Cited March 9, 2021.

17. A. Y. Chahg, V. F. Skirbekk, S. Tyrovoras, et al., "Measuring population ageing: An analysis of the Global Burden of Disease Study 2017," Lancet Public Health 4, e159-e167 (2019).

18. V. G. Dobrokhleb and V. N. Barsukov, " Population aging in Russia and China: Features and socioeconomic risks," Uroven' Zhizni Nas. Reg. Ross., No. 4, 36-48 (2020).

19. O. N. Bobrovskaya, "On strategic objectives of Russia and Japan's experience in creating jobs for citizens of a new age of working capacity: Economic and legal research," Uspekhi Gerontol. 32 (6), 870-881 (2019).
20. Old age in the regions of Russia.

https://static.tochno.st/files/analytical/b4604fa2f20405af96fd2ee17a99172a.pdf. Cited May 27, 2021.

21. Yu. V. Dudovtseva, "Strategic analysis of trends in the labor market of the older generation," Upr. Konsul'tirovanie, No. 1, 93-103 (2020).

22. V. G. Dobrokhleb, "Welfare state and the older generation of Russia: Declared and implemented principles," Ekon. Nalogi. Pravo, No. 14, 64-71 (2021).

23. A. V. Yurevich, "Old age as an interdisciplinary problem,” Vestn. Ross. Akad. Nauk 89 (1), 49-55 (2019).

24. O. A. Voronina, "Construction and deconstruction of gender in modern humanitarian knowledge," Vestn. Perm. Univ. Filos. Psykhol. Sotsiol., No. 1, 5-16 (2019).

25. Civil Society Review on SDG Implementation in Russia. http://kurs2030.ru/en/report2020. Cited March 14, 2021.

26. Order of the Ministry of Labor and Social Protection of the Russian Federation of July 18, 2019, No. 512n, On Approval of the List of Industries, Jobs, and Positions with Harmful and (or) Dangerous Working Conditions That Limit the Use of Women's Labor. https://mintrud.gov.ru/docs/mintrud/orders/1366. Cited March 14, 2021.

27. The Global Gender Gap Report 2020. http://weforum.org. Cited March 10, 2020.

28. Global Wage Report 2018/19: What lies behind gender pay gaps. http://Ilo.org. Cited March 10, 2020.

29. Confederation of Labor of Russia. http://ktr.su. Cited March 30, 2020.

30. Transparency International in Russia. http://transparency.org.ru. Cited March 19, 2020.

31. S. Arber, "Gender and ageing in global context: Role of marital status," Translated by E. V'yugovskaya and A. Ipatova, Monitoring Public Opinion: Econ. Soc. Changes, No. 2, 59-78 (2016).

32. Latest data on coronavirus worldwide. Distribution table and map. How many people got sick, the number of victims, how many recovered. https://meduza.io/feature/2020/03/05/poslednie-dannye-po-koronavirusuvo-vsem-mire-tablitsa. Cited March 5, 2021.

33. Russians named the age when old age comes. https://www.m24.ru/news/obshchestvo/04122020/144235?utm_source=smi2\&utm_campaign=video\&utm_medium $=$ exchange. Cited March 5, 2021.

34. O. V. Krasnova, The Psychology of Old Age and Aging (Akademiya, Moscow, 2004) [in Russian].

35. Russians spoke about changes in life after the adoption of amendments to the Constitution. https://lenta.ru/news/2020/12/11/poprvki. Cited May 5, 2021.

Translated by B. Alekseev 